\title{
Delivery truck drivers' work outside the cab: psychosocial discomforts and risks based on participatory video analyses
}

\author{
Jose Manuel Ojel-Jaramillo Romero ${ }^{*}$, Arto Reiman², Jose Juan Cañas Delgado³, Seppo Väyrynen²,
} Janne Pekkala ${ }^{2}$ and Mikael Forsman ${ }^{4}$

\begin{abstract}
Purpose: Delivery truck drivers face various physical and psychosocial discomforts and risks in their work. Psychosocial perceptions are linked to physiological and psychological loads_-strain and stress_affecting drivers throughout various mechanisms within activities and conditions. In this study, participatory video-assisted analyses were utilised for identifying psychosocially demanding work situations that delivery truck drivers encounter outside the cab.

Methods: Identifications were made by the drivers from previously recorded videos of their own work in their daily work environments. In addition, other stakeholders, such as managers and designers, also identified situations. The video identification data were further processed by the researchers, showing differences between the perceptions of the drivers and stakeholders on the causal conditions and intervening conditions behind the discomfort identifications.

Results: All together 99 identified situations-over half (53\%) of which included a fear of causing different types of undesired events with risks of losses, such as human injuries or material damages. The results showed not only do risks and discomforts exist in demanding work situations, which seemed relevant, but they also indicated the importance of involving different stakeholders.

Conclusions: This study provides a unique methodological approach, as video observations and analyses and qualitative data analysis are combined to provide more in-depth data with visualizations into risk management processes.
\end{abstract}

Keywords: Delivery transportation, Discomfort, Psychosocial stress factors, Risk management, Stakeholder, Truck drivers, Video analysis

\section{Introduction}

Delivery truck drivers face various kinds of physical and psychosocial stress factors in their work [1, 2]. Stress factors may arise from different origins. The work system theory provides a holistic approach on discussing humans and their work environments in which the work is performed and the technology and tools that are used to perform defined work tasks under certain organizational conditions [3, 4]. Work systems have

\footnotetext{
* Correspondence: jmojeljara@gmail.com

${ }^{1}$ Unit4 Business Software, Granada, Spain

Full list of author information is available at the end of the article
}

been discussed in the delivery transportation context by e.g. Reiman et al. [1] and Murphy et al. [2].

Work systems are often discussed as sociotechnical systems where various individuals interact [5]. In ergonomics literature a categorization of personnel, technological, environmental, internal environmental and organizational subsystems is used when sociotechnical systems are discussed in macroergonomics, i.e. organizational and interorganisational contexts [6]. Changes in any of these subsystems may have direct or indirect impacts to occupational health and safety [7].

A transport system is comprised from elements such as artifacts and infrastructure, knowledge, regulatory 
aspects and different networks [8]. Similarly, compared to the work system theory, these elements may affect occupational health and safety. The quality of the infrastructure, e.g. trucks, roads, courtyards and premises may vary and change over time. Knowledge is related to organizational processes and personnel skills. For example, when new technology is applied, knowledge how to use it safely is needed. Thus, an interorganisational sociotechnical work system can be referred to a transport system. In this study, the focus is on identifying psychosocial discomfort factors in related to individual delivery driver's work systems outside the cab. This human-centred approach is further expanded to organizational and interorganisational risk management processes.

\subsection{Background}

Delivery truck drivers work in several different work environments during their work shift [9-12]. Besides routine driving tasks, delivery drivers' work is performed at terminals; in common areas such as streets, roads, and pavements; and on customers' premises as well as in buildings of wholesalers and retailers [13, 14]. In delivery transportations, drivers encounter demands for productivity and quality and the challenges of human well-being most often while working alone. Work phases-loading at the main terminal, driving, and unloading at customers' premises-take up rather even shares of the total time of the driver's work shift (Fig. 1) [11, 15]. Loading and unloading tasks entail predominantly manual work activities. Different kinds of aids and tools are used to ease the work. These include solutions that are embedded within the truck body structures, such as tailgate loaders and ladders. In addition, manual material handling tools, such as hand trucks, pallet trucks, and roll cages, are used in moving the cargo $[9,11,16]$. In addition to manual activities tasks such as the treatment of material flows and the differentiation of goods for the final customer may be included in delivery truck drivers' work [17].

Delivery truck drivers have only limited possibilities to control their work pace. A research report by the European Agency for Safety and Health at work [18] shows that roughly two-thirds of all employees in general in the European Union area reported that they were able to choose and change the order of their work tasks, whilst in the transportation industry only half of the respondents reported the same. In line with this finding, employees in the land transport branch also reported a lower-than-average ability to choose or change their methods of work-50\% and $67 \%$, respectively. Finally, in terms of choosing or changing one's speed or rate of work, again, land transport workers rated lower than the average: $64 \%$ and $69 \%$, respectively [18].

According to Croon et al. [19], the intensification of the work of truck drivers is related to an increased demand for time-sensitive deliveries accompanied by the emergence of the 24-h economy. In addition, various other external, organizational and regulatory forces can be associated influencing the drivers [20]. Further, as the drivers can be considered as lone workers, they often face ethical decision-making situations where they can

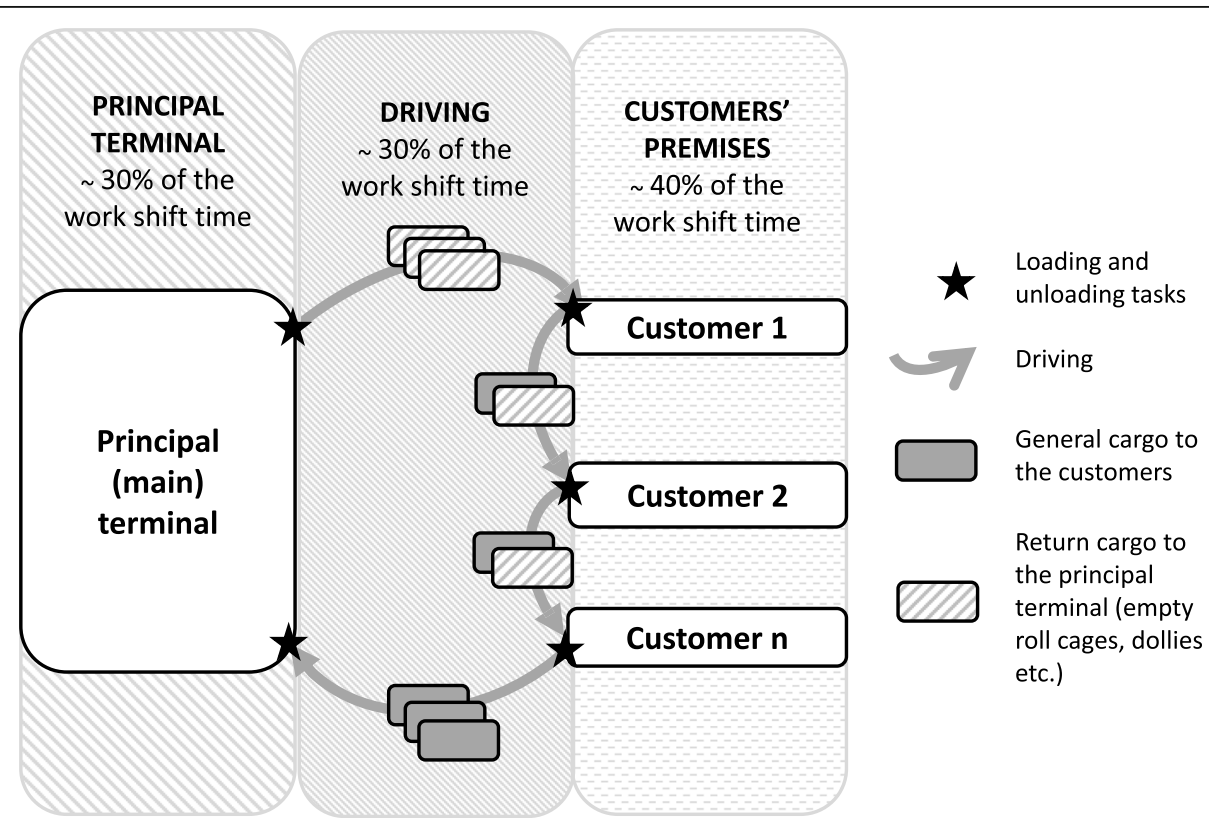

Fig. 1 Simplified illustration of a delivery process based on Pekkala [11]. There are three main work phases in truck drivers' routine, daily work: unloading and loading at the principal (main) terminal or warehouse, driving, and unloading and loading at different customers' premises 
choose whether to perform certain work tasks safely or unsafely to ease or fasten their work [20,21]. According to the job demands and control models put forth by Karasek and Theorell [22] and Croon et al. [19], the psychological demands result in psychological strain and physical illness only when the level of decision latitude, later referred to as job control, is low [19]. Further, it is important to discriminate between psychosocial stress caused by underload and overload; the former leads to reduced alertness and lowered attention and the latter to distraction, diverted attention, and insufficient capacity and time for adequate information processing [23].

Truck drivers are key actors in the flow of goods throughout the supply chain. Still, too little attention has been paid to their well-being and work ability [24]. Anderson [21] urges to broaden in the focus from traditional occupational health and safety considerations to psychological and managerial aspects when studying truck drivers' work. In this study, concrete sources of psychosocial strain and stress factors in delivery transportation work are identified. Specifically, the focus is on work performed outside of the cab. The case material is from the Nordic environment. Thus, it is assumed that there are certain tasks that contain characteristics (such as winter conditions) that are dependent on the geographical location and seasonal variation. This study aims to identify psychosocial discomforts in truck drivers' work outside the cab by utilizing participatory video observations. These identifications are further analysed to create a risk management model for psychosocial risks at delivery transportations.

\section{Methods and materials}

\subsection{General}

This study is based on in-depth re-analyses of the video material on delivery truck drivers' work that was reported by Reiman et al. [1]. In that study [1], delivery truck drivers' own identifications of physical and psychosocial discomforts were analysed by identifying certain physical activities and deviations that had led to the discomfort. In the present study, the focus was strictly on the psychosocial discomfort identifications and their verbal descriptions.

\subsection{Data collection}

The data were collected with the Swedish participatory ergonomics video analysis method and tool VIDAR (a Swedish abbreviation for "Video- and computer based work analysis"; see [24]). VIDAR is a participatory ergonomics observational method for assessing workload through identifications of physical and psychosocial discomfort $[24,25]$.

The data collection for the video analyses was performed through separate filming occasions $(N=21)$ in midwinter 2008. During the data collection, the researchers followed delivery truck drivers on their daily driving routes and filmed all occasions when the driver was working outside the cab. The data were primarily collected between the early hours and late afternoon of the day. All work outside the cab during a delivery was videotaped except for a few occasions in which the customer companies refused to allow video-filming on their premises, for instance, due to security reasons. The video material was later edited (i.e., similar kinds of recurring work tasks were excluded) for psychosocial discomfort identification and analysis purposes. Video analysis sessions were conducted within a few days after the filming occasion.

The video analysis data were collected from the practices of three companies' delivery transportation actions. The companies and the drivers were selected because of their willingness to improve the drivers' work. The companies selected the drivers based on their voluntariness. However, schedules for the video filming occasions were decided by the researchers. The companies were considered typical in Finland.

\subsection{Data analysis}

The identifications of psychosocial discomforts were analysed in the analysis sessions utilizing the internal psychosocial criteria included in the VIDAR method and tool (see Table 3 in Appendix 1). The internal criteria consist of nine alternatives for sources of psychosocial discomfort, including 1) time pressure, 2) obstruction/ interruption/disturbance, 3) uncertainty, 4) poor control, 5) lack of response/feedback, 6) risks, 7) it is emotionally tough, 8) the task is boring or meaningless, and 9) other. The given alternatives are based on the action theory by Karasek and Theorell [22], in which the stressors are circumstances that disturb the goal-directed regulation of actions. The alternatives may contain sub-alternatives to define the discomfort more precisely. In addition, each identified discomfort was given a verbal description and special observations by the evaluator.

VIDAR analysis sessions were arranged for eight individual delivery truck drivers and for four interest groups (drivers [different from the drivers in the individual analyses], drivers' immediate superiors, safety group members, and cargo space designers). The session classes were designated the "individual drivers group" and the "stakeholder group." Individual drivers analysed edited video material from his/her own work, and in the group sessions edited video material representing each delivery truck driver's work at their company was used.

A grounded theory approach was applied for further in-depth analyses. Grounded theory uses detailed procedures for analysis $[26,27]$. In this study, three phases of coding [28] —open, axial, and selective-were performed for the identified psychosocial discomforts. In the open 
coding phase, researchers examined the identification database (including internal criteria selections and verbal descriptions and special observations for each identification) and text for salient categories of information. Using the constant comparative approach, the researcher attempted to "saturate the categories". In the axial coding phase, researchers reviewed the data to provide specific coding categories that related to or explained the central phenomenon, causal conditions, and strategies for addressing the context and intervening conditions and the consequences. This analysis was carried out separately for two evaluator groups-drivers and other stakeholders. Finally, based on the coding phases a risk management model was derived from the data.

\section{Results}

\subsection{VIDAR-identified psychosocial discomforts of delivery} truck drivers' work

In all, 99 identifications of different psychosocial discomforts were produced in the analysis sessions. These 99 identifications contained a total of 150 selections of alternatives or sub-alternatives (Table 1). Over a half $(53 \%)$ of the identifications included a psychosocial discomfort of "fear of causing risks." From those the sub-alternatives, "fear of causing own accident" (28\%) and "fear of causing economic damage" (13\%) were emphasized. The proportion of "fear of causing risks" was higher $(63.1 \%)$ in the driver group than in the stakeholder group (43.9\%). In the stakeholder group, identifications related to "obstruction, interruption, and disturbance" were also emphasized (33.8\%).

\subsection{Analysis of the identified discomforts}

From the 99 identified discomforts, a total of 60 discomforts included more in-depth verbal descriptions of the working situations by the subjects. Only these identifications were used in the further analyses, and the rest were excluded. Short verbal descriptions of the identifications are presented in Table 4 in Appendix 2.

As examples related to cargo, insufficient knowledge on the placement of the goods inside the terminals and deficiencies in locating certain packages in the cargo space were identified as discomfort factors slowing down the work. In addition, uncertainty of the proper ways to handle different sized cargo was identified causing psychosocial discomfort. Inadequate tools and technologies, such as the ones related to cargo spaces (e.g. floor hooks, cargo space doors) and to the equipment used (e.g. cages, tailgate loader) were identified as discomfort factors affecting efficiency but also as potential risks for accidents. Different work environments (such as cargo spaces) and other environments (public roads, customer's environments) were identified as sources of discomforts. For instance, constant accident risks for falling or slipping from the tailgate loader or the cargo space or at unsafe customers' premises and courtyards were identified causing psychosocial discomfort. Drivers own decisions to act unsafely were often identified as possible discomfort causes in the stakeholder group identifications. Often that was recognised to relate to poor training or instructions. However, drivers' own decisions to act in an unsafe manner were also identified. Table 2 contains the results of the axial coding for the groups.

A labour risk can be provoked by poorly planned tasks and inadequate guidance, such as the stress related to performing tasks in time, improper working manners and the amount of tasks and interruptions while performing the work. These tasks are performed in different work environments, in which the risk can be evoked by unsafe physical work environment issues, such as bad lighting, darkness and wintertime conditions. Further, work environments where unloading tasks are performed may be used for other purposes, such as a temporary store room, or they have not been designed for unloading purposes at all. The work environments also include concrete risks for accidents. Organizational issues evoking risks arise from poor company communication, lack of resources, and unclear and undefined processes. In addition, work equipment and technology may evoke risks in relation to, for example, poor usability and improper tools. These risks may lead to injuries and accidents. In addition to occupational accidents, property and economic damage may also occur. In addition to injuries and accidents, criticism from others (co-workers, management, customers, other stakeholders) may also transpire from the identified risks and discomforts. Thus, a broad risk management process taking into account all the above-mentioned aspects is required to avoid accidents and injuries. A holistic work system approach allows categorization for these risk management aspects. This process is presented in a form of a risk management model in Fig. 2.

\section{Discussion}

Various physical and psychosocial discomfort factors and their combinations can be associated to delivery drivers' work [29]. In addition to enabling adverse health effects to humans, psychological discomfort factors have been associated with low performance at work; as such, psychosocial work characteristics have a strong relationship with productivity loss [30]. The mitigation (or elimination) of risks and discomforts leads to more optimal work systems, with higher expectations in terms of productivity, quality, and conformity [3]. Before risks can be mitigated or eliminated, they must be identified. The aim of this study was to provide a participatory analysis to identify psychosocial discomforts in delivery truck drivers' work 
Table 1 Identified psychosocial discomforts

\begin{tabular}{|c|c|c|c|c|}
\hline & $\begin{array}{l}\text { Identified situations } \\
\text { by the driver group ( } \mathrm{n} \text { ) }\end{array}$ & $\begin{array}{l}\text { Identified situations by } \\
\text { the stakeholder group (n) }\end{array}$ & Total $(n)$ & $\%$ (main criteria) \\
\hline 1. Time pressure & & & 4 & 2.7 \\
\hline 1.1 Bad planning & 2 & 1 & & \\
\hline 1.2 Too much to cope with at the same time & 1 & & & \\
\hline 2. Obstruction/Interruption/Disturbance & & & 40 & 26.2 \\
\hline 2.1 Tools, aids, non-working machines & 7 & 11 & & \\
\hline 2.2 Difficulty reaching, difficult to get to & 5 & 6 & & \\
\hline 2.3 Lack of specifications or knowledge & 2 & 3 & & \\
\hline 2.4 Others have not done their job & 3 & 1 & & \\
\hline 2.5 Noise, idle talk, or light reflection & & 2 & & \\
\hline 3. Uncertainty & & 10 & 10 & 6.7 \\
\hline 4. Poor control & & & 1 & 0.7 \\
\hline 4.1 Too little influence over what I should do & & 1 & & \\
\hline 5. Lack of response/feedback & & & 1 & 0.7 \\
\hline 5.1 Need response from boss & & 1 & & \\
\hline 6 Risks & & & 79 & 53.0 \\
\hline 6.1 Risk of own accident/injury & 26 & 16 & & \\
\hline 6.2 Risk of other/others being harmed & 9 & 3 & & \\
\hline 6.3 Risk of causing economic damage & 12 & 8 & & \\
\hline 6.4 Risk of criticism from fellow workers or boss & 3 & 2 & & \\
\hline 7. It is emotionally tough & 3 & 1 & 4 & 2.7 \\
\hline \multicolumn{5}{|l|}{ 8. The task is boring or meaningless } \\
\hline 9. Other & & & 11 & 7.4 \\
\hline 9.1 Limited spaces & 8 & & & \\
\hline 9.2 Long distances & 1 & & & \\
\hline 9.3 Incorrectly designed door & 2 & & & \\
\hline Total N & 84 & 66 & 150 & 100 \\
\hline
\end{tabular}

outside the cab and to deepen that knowledge by further analyses. As such, this study presents a process in which psychosocial discomforts and risks can be identified and analysed by different stakeholders inside the transportation company and within the value chain. Further, the results can be used to facilitate strategic risk management and value chain management processes.

Value chains consist of series of activities that create and build value [31]. Transportation work can be considered a part of a value chain. A transportation company, like any company $[1,2]$, can be thought of

Table 2 A summary of the axial coding phase

\begin{tabular}{lll}
\hline & Driver group & Stakeholder group \\
\hline Phenomenon & Labour risk & Labour risk \\
Identified causal conditions & Stress, poor accessibility, darkness, inadequate & Poor communication practices, unclear processes \\
& tools and technologies, too many tasks, & bottlenecks, too many interruptions \\
Identified context-related issues & Deficiencies in the work environments, loading & Deficiencies in the work environments, loading \\
& and unloading tasks, wintertime & and unloading tasks \\
Identified intervening conditions & Lack of resources, poor work environments, & Poor assistance from others \\
& poor assistance from others & \\
\hline
\end{tabular}




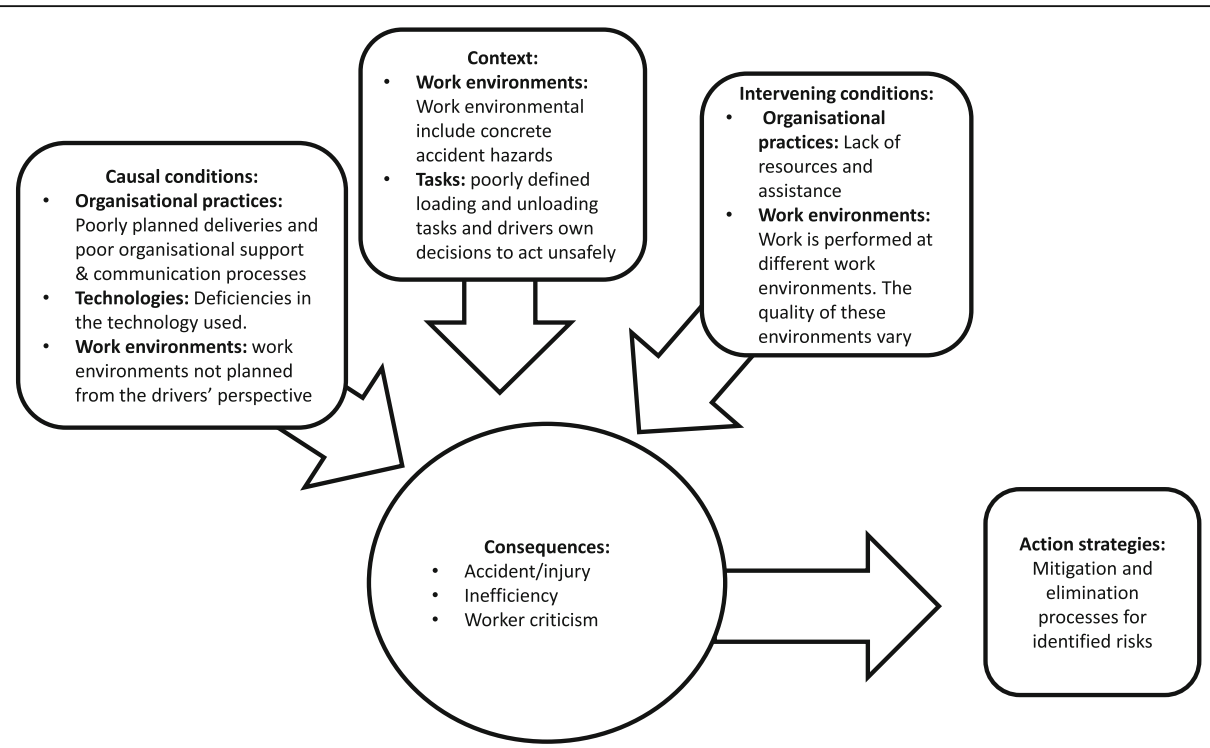

Fig. 2 The risk management model for psychosocial discomforts

and analyzed as a constellation of individual work systems interacting with each other in the value chain. Based on this perspective, the truck and the driver are naturally in the centre of such work system, a very special one of varying character. Carayon and Smith [3] purport aiming at balanced work systems at an individual level and further at organization level. They define a balanced organization as one that takes into account business goals and human outcomes, that examines the positive and negative aspects of work system design, and that minimizes negative outcomes like all non-conformities, such as errors, disturbances, accidents, and incidents (related to personnel, goods, devices, and/or the work environment).

Risks and discomforts are signs of possible imbalances in the work systems. The video analysis tool utilized in this study can be used to identifying risks and discomfort factors, but also other development needs for delivery drivers work. Thus, not only improvements but innovations as well could be approached through this participatory process. For instance, Goffin and Mitchell [32] present many definitions of innovation. The characteristic feature of most definitions is "introducing something new" as far as technology (i.e., products) is concerned. However, innovations comprise (business) processes and services, as well as products [32].

This study shows the labour risk from the perspectives of the two groups (drivers and stakeholders), firstly, that there was no agreement between the groups regarding causal conditions. The drivers' group reported more concrete issues, including poor accessibility, darkness, difficult tools, too many tasks, bottlenecks, and too many interruptions; while the stakeholders reported organizational issues, including poor company communication and unsuitable processes. In terms of intervening conditions, there was agreement between the groups on the importance of the availability of resources; however, only the drivers also reported the lack of facilities aspect. Based on this, we emphasize that labour risk must be analysed from different perspectives of the value chain. If not all stakeholders are included, long-lasting and effective solutions are hard to achieve.

One possible next step towards an innovative design of holistic work systems in delivery transportation could be to aim at producing delivery truck drivers' work system(s) scenarios with potential risk descriptions to facilitate discussion on discomfort mitigation or elimination solutions. These solutions could be evaluated by relevant groups of drivers and stakeholders with a participatory approach, as Rajala and Väyrynen [33] did in their trials at metal industry.

\subsection{Contributions to risk management}

Risk management is a complex process that must be led by top management. Risk management aims at finding solutions to mitigate and/or remove risks. A key question is to find models and tools for risk identification purposes. The psychosocial discomforts identified in this study were most often related to different types of risks and the fear of causing such 
risks. Drivers work in various environments, in which other people, such as other workers, pedestrians, and cyclists are present. This applies both at driving and loading and unloading work phases (refer to [34]). The behavior of such people can be unpredictable. These people cannot be systematically removed and/ or restrained from drivers' work environments. Thus, other risk mitigation choices must be made. Drivers must be aware of the possible risks during the loading and unloading phases, and they must know how to deal with the risks concerning other people in their work environments. We identify this as a future research challenge 1 (RC1). Informing and training are two risk mitigation measures that can be used for such purposes. In addition, managerial decisions on, for example, route and task planning can be made for risk mitigation purposes; often this also requires discussion with clients. The need for improving stakeholder discussion processes is highlighted as the second research challenge (RC2).

In addition to be used in improving delivery truck drivers' skills and awareness, the work system model enables systematic intra- and interorganisational development approaches. Risks and discomforts can be categorized by the work system elements. The categorization helps in prioritizing risk management actions. In this study, a large proportion of the risks identified was related to vehicles and their structures, such as cargo spaces and tailgate loaders. Drivers might fear causing damage, and a lack of adequate tools might cause psychosocial discomfort. Thus, a more in-depth discussion is needed between drivers and transportation companies and with the stakeholders that design and manufacture technologies and work equipment. Developing collaboration processes between designers and end-users is emphasised as the third research challenge (RC3). Technological development and possibilities risen by the digitalization may bring out possibilities for various development paths. A participatory video-assisted analysis process is an approach that produces in-depth knowledge with visual material that can be used in design processes to facilitate better collaboration processes between the technology designers and drivers as end-users.

In addition to technologies and equipment, the different types of work environments on the customers' premises or in the common areas where the driver performs manual delivery work also possess risks. Limited spaces, long distances, and bad planning are some of the related psychosocial risk factors causing mainly psychosocial overload by e.g. distraction, rush and malfunctioning technology. Such psychosocial discomfort factors reduce the possibilities for the driver to adjust their working manners and pace during the work day. Work environment related development needs are highlighted as the fourth future research challenge (RC4).

It is surprising, and against our original assumption, that wintertime conditions were included in only a few identifications (6 out of the 60 analysed identifications) as a risk or discomfort factor. A commonality among all these discomforts is that they are more or less related to bad planning, especially in terms of premises, logistics, and tools. These discomforts and risks can usually be easily removed, or at least mitigated, with better planning and cooperation among all the interested groups in the value chain. Winter conditions is identified as a special research challenge for certain areas (RC5).

\subsection{Limitations}

Some limitations were identified concerning this study. Firstly, the identifications are analysed utilizing internal criteria. It is possible that a possibility to open answers could have provided more ample descriptions. However, it should be noted that the possibility for verbal descriptions was offered to complement inner criteria. Secondly, the amount of data is rather restricted, as only three transportation companies were included due to budget restrictions. Thus, it is questionable how generalizable the results are. Nonetheless, the companies included represented typical delivery transportation companies in Finland. Thirdly, the video material was collected in winter and spring conditions, thus possible problems related to weather condition factors may be over-emphasized. Nonetheless, our analysis shows that only $10 \%$ of the identifications contain characteristics that can be associated with Nordic winter conditions. Fourthly, the data was collected in 2008. Thus, there is a possibility that due to technological development not all of the identifications are valid anymore. However, the delivery drivers' work is still based on physical work activities and very little development has been made to the assisting work equipment. Neither the varying work environments have changed. Deliveries are still made to various locations from which the quality of the work environment varies (refer to [20, 21]). Fifthly, the video material was edited by the researchers (JP and AR) to facilitate efficient video analysis sessions. Thus, there is a possibility that the researchers own perceptions while editing the data might have affected the analysis data. Based on researcher group's experiences, video analyses take around three to four times the duration of the video material (i.e. one hour of video material is analyzed in 3 to $4 \mathrm{~h}$ ). Video editing was done for practical 
reasons, as it was not possible to recruit the participants for longer analysis sessions. Sixthly, video cameras have a limited field of vision (refer to [35]). Thus, there is a possibility that not all affecting elements were captured. Lastly, the analyses were based on subjective assessments. Nonetheless, various evaluators participated and material was discussed as an entity. This lowers the possibilities for misjudgement. In addition, the amount of evaluators in this study is equal or higher when referred to similar kinds of study settings $[15,24]$.

\section{Conclusions}

The results showed not only do risks and discomforts exist in demanding work situations, which seemed relevant, but they also indicated the importance of involving different stakeholders. Further, this study provides a unique methodological approach, as video observations and qualitative analysis are combined to provide more in-depth data with visualizations.

Regarding the risk management model, the main causal conditions of the psychosocial labour risks are related to the nature of the task and communication problems within the company. Thus, it is important for companies to establish different strategies to mitigate such risks, as causal conditions can affect the productivity, conformity, and quality of the work. An interesting area for future research might be the study of psychosocial discomfort identifications and their relationship to non-productivity and non-conformity regarding quality criteria.

\section{Appendix 1}

Table 3 Inner criteria

1. Time pressure

1.1 Bad planning

1.2 Too much to cope with at the same time

2. Obstruction/Interruption/Disturbance

2.1 Tools, aids, non-working machines

2.2 Difficulty reaching, difficult to get to

2.3 Lack of specifications or knowledge

2.4 Others have not done their job

2.5 Noise, idle talk, or light reflection

3. Uncertainty

4. Poor control

4.1 Too little influence over what I should do

5. Lack of response/feedback

5.1 Need response from boss

6 Risks

6.1 Risk of own accident/injury

6.2 Risk of other/others being harmed

6.3 Risk of causing economic damage

6.4 Risk of criticism from fellow workers or boss

7. It is emotionally tough

8. The task is boring or meaningless

9. Other

9.1 Limited spaces

9.2 Long distances

9.3 Incorrectly designed door 


\section{Appendix 2}

Table 4 Summary of the identifications in the drivers' group

\begin{tabular}{ll}
\hline ID & Short description of the situation where the discomforts occurred \\
\hline 1 & $\begin{array}{l}\text { Crowded facilities at the principal terminal creates strain and tension while performing } \\
\text { loading tasks. }\end{array}$ \\
3 & $\begin{array}{l}\text { Poor identification of the goods inside the terminal. The driver is forced to search the goods } \\
\text { while performing loading. }\end{array}$ \\
4 & Narrow premises. Not possibilities to use tail gate loader. Risk of slipping and being hurt \\
5 & $\begin{array}{l}\text { Difficult to reach control switches while using the tailgate loader, as they are on the other } \\
6\end{array}$ \\
7 & Difficulties in securing the load. Floor hooks frozen or rusted. \\
8 & Difficulties in securing the load. Lack of supplies for binding the cargo. \\
9 & Difficulties in securing the load. Mounting hooks below the cargo space not available in all \\
10 & Uneven ground. Danger of slipping while descending the cargo space. \\
11 & Time pressure. Monday distributions are usually very busy.
\end{tabular}

12 Unsafe tailgate loader. Risk of hurting foot by accidentally placing it under the tailgate loader while it is being lifted.

13 Unsafe customer premises. The cooling cabinet is shallow and it is possible to knock head. Driver has to walk by stooping back and neck.

15 The driver may tumble while performing manual lift is performed incorrectly in the cargo space. Sometimes the driver has to warn other people not to come too near the truck.

17 Unsafe public environment. Crossing a public road with the goods. Unsafe loading practices. Five boxes have been piled one on the other. Possibility of falling. Unsafe working practices. Handling a light load that is difficult in size and shape. Unsafe working practices. There is a light in the cargo space but the driver tends not to switch it on.

21 Unsafe unloading practices at customer's premises. Not possibilities to use the tailgate loader. There is a potential risk of being injured by falling under the load. A very narrow space inside the lift at a customer's premises and goods must be distributed to several floors. Small space to perform unloading at a customer's courtyard. Unsafe working methods. Very large items must be pulled one or two times in a work shift. Unsafe work environments. Working with heavy loads at the tailgate loader in wintertime.

Fear that a roll container or a similar load may fall from the tailgate loader or from the cargo space when the vehicle is in a tilted position. dock to save time if there is only one package to be delivered. route for pedestrians. Poor visibility and parking arrangements are inadequate. 
Table 4 Summary of the identifications in the drivers' group (Continued)

\begin{tabular}{|c|c|c|}
\hline ID & Short description of the situation where the discomforts occurred & $\begin{array}{l}\text { Identification contains characteristics } \\
\text { specific to Nordic environments }\end{array}$ \\
\hline 32 & $\begin{array}{l}\text { Loading at the principal terminal. The plots are small relative to the large amount of the } \\
\text { goods. Scheduling routes is thus difficult. }\end{array}$ & \\
\hline 33 & The driver is forced to seek for goods inside the terminal. & \\
\hline 34 & The driver must find ways for handling of over-long items. & \\
\hline 35 & Some of the items to be delivered are stored outside and must be sought. & \\
\hline 36 & $\begin{array}{l}\text { When the side of the cargo space is open at customer's premises while unloading, there is a } \\
\text { risk of the cargo falling. Bad lighting worsens the situation. }\end{array}$ & \\
\hline 37 & $\begin{array}{l}\text { Unsafe truck body structures. Steps are not included in all vehicle models and the driver } \\
\text { must adapt. Foot slips easily. }\end{array}$ & \\
\hline 38 & Gear box fixing and the door latch are weak. The driver faces a possibility for hurting himself. & \\
\hline 39 & $\begin{array}{l}\text { Problems related to connecting the trailer to the truck. Clothes get dirty and there is a } \\
\text { possibility to hurt hands or head. The placement of plugs may vary by manufacturer. }\end{array}$ & \\
\hline 40 & Pallet truck has not been fastened properly inside the cargo space. & \\
\hline 41 & $\begin{array}{l}\text { Placement for different accessories varies inside the cab. The driver may need to adapt to } \\
\text { different work environments. }\end{array}$ & \\
\hline 42 & $\begin{array}{l}\text { The driver does not know how to use ICT devices used for reporting after unloading the } \\
\text { goods at customers' premises. }\end{array}$ & \\
\hline 43 & The cargo is not fastened properly because of the difficult shape of the item. & \\
\hline 44 & Difficult shaped item. Fastening the item is difficult and the driver acts unsafely. & \\
\hline 45 & The driver is fastening the load incorrectly. Guidance to drivers insufficient. & \\
\hline 46 & $\begin{array}{l}\text { Hooks are icy and placed poorly inside the cargo space. May force to improper load } \\
\text { fastening solutions. No assistive devices available. }\end{array}$ & $x$ \\
\hline 47 & Moving heavy items alone is difficult and contains many risks at a customer's premises. & \\
\hline 48 & The driver is uncertain about the binding point inside the cargo space. & \\
\hline 49 & $\begin{array}{l}\text { Poor communication. When the driver is unloading cargo that has been fastened by } \\
\text { someone else, he/she can't be absolutely sure if it has been fastened safely. }\end{array}$ & \\
\hline 50 & The driver chooses not to use the tailgate loader while ascending the cargo space. & \\
\hline 51 & The driver is uncertain about the load securing process. 12 m-long metal pipes are difficult to fasten. & \\
\hline 52 & $\begin{array}{l}\text { Different kinds of pushcarts available, however the driver chooses not to use them for } \\
\text { unloading purposes. }\end{array}$ & \\
\hline 53 & Difficulties to reach while using pushcarts inside narrow cargo space. & \\
\hline 54 & Unsafe loading dock at a customer's premises. Possibility of falling from the tailgate loader. & \\
\hline 55 & Installing and lifting cargo space supporters is difficult. Jammed supporters will rip out. & \\
\hline 56 & Location of the gas tank is problematic. Difficulties when refuelling. & \\
\hline 57 & Poor lighting at public streets and the unloading work must be performed on the street. & \\
\hline 58 & $\begin{array}{l}\text { Customer's narrow premises force the driver to move other items out of the way before he/ } \\
\text { she can start unloading, }\end{array}$ & \\
\hline 59 & Pulling a roll cage on a public street in slippery conditions. & $x$ \\
\hline 60 & $\begin{array}{l}\text { The driver is forced to deliver goods inside narrow premises (in this case, a small shop) } \\
\text { among clients. }\end{array}$ & \\
\hline
\end{tabular}

\section{Acknowledgements}

The research was funded by the Finnish Work Environment Fund, the Finnish Funding Agency for Technology and Innovation, the Ministry of Social Affairs and Health, and the participating companies.

\section{Authors' contributions}

JMO-JR carried out the data analyses and drafted the manuscript. AR and JP collected the empirical data, participated in the data analyses and manuscript preparation. JJCD, SV and MF participated in the design of the study, data analyses and manuscript preparation. All authors read and approved the final manuscript.

\section{Competing interests}

The authors declare that they have no competing interests. 


\section{Publisher's Note}

Springer Nature remains neutral with regard to jurisdictional claims in published maps and institutional affiliations.

\section{Author details}

${ }^{1}$ Unit4 Business Software, Granada, Spain. ${ }^{2}$ Industrial Engineering and Management, University of Oulu, PO BOX 4610, 90014 Oulu, Finland. ${ }^{3}$ University of Granada, Granada, Spain. ${ }^{4}$ Institute of Environmental Medicine, Karolinska Institutet, Solnavägen 4, 11365 Stockholm, Sweden.

Received: 13 September 2017 Accepted: 15 May 2018

Published online: 13 June 2018

\section{References}

1. Reiman A, Pekkala J, Väyrynen S, Putkonen A, Abeysekera J, Forsman M (2015) Delivery truck Drivers' and stakeholders video-assisted analyses of work outside the truck cabs. Int J Sustain Transp 9(4):254-265

2. Murphy LA, Huang Y-h, Robertson MM, Jeffries S, Dainoff MJ (2018) A sociotechnical systems approach to enhance safety climate in the trucking industry: results of an in-depth investigation. Appl Ergon 66:70-81

3. Carayon P, Smith M (2000) Work organization and ergonomics. Appl Ergon 31(6):649-662

4. EN ISO 6385 (2004) Ergonomic principles in the design of work systems. In: European committee for standardization

5. Kleiner BM (2008) Macroergonomics: work system analysis and design. Hum Factors 50(3):461-467

6. Kleiner BM, Hendrick HW (2008) Human factors in organizational design and management of industrial plants. Int J Technol Hum Interact 4(1):114-128

7. Murphy LA, Robertson MM, Huang Y-h, Jeffries S, Dainoff MJ (2018) A sociotechnical systems approach to enhance safety climate in the trucking industry: development of a methodology. Appl Ergon 66:82-88

8. Auvinen $\mathrm{H}$, Tuominen A (2014) Future transport systems: long-term visions and socio-technical transitions. Eur Transp Res Rev 6(3):343-354

9. McClay RE (2008) Truck falls: examining the nature of the problem. Prof Saf 53(5):26-35

10. Shibuya $H$, Cleal B, Kines $P$ (2010) Hazard scenarios of truck drivers' occupational accidents on and around trucks during loading and unloading. Accid Anal Prev 42(1):19-29

11. Pekkala J (2008) Jakelukuljettajan ohjaamon ulkopuolisen työn videoavusteinen ergonomia-, käytettävyys- ja turvallisuusanalyysi Video-assisted analysis of ergonomics, usability and safety in the driver's distribution work done outside of the truck's cab], Diploma thesis, University of Oulu, Oulu

12. Reiman A, Pekkala J, Väyrynen S (2010) Short haul drivers' work and different work environments outside the cab- New tool for two-say assessments. In: Bradley, G. (ed) Proceedings of IADIS International conference ICT Society and Human Beings. Freiburg, IADIS Press.

13. Olson R, Hahn Dl, Buckert A (2009) Predictors of severe trunk postures among short haul truck drivers during non-driving tasks: an exploratory investigation involving video-assessment and driver behavioural selfmonitoring. Ergonomics 52(6):707-702

14. Pitera K, Pokorny P, Kristensen T, Bjørgen A (2017) The complexity of planning for goods delivery in a shared urban space: a case study involving cyclists and trucks. Eur Transp Res Rev 9(9). https://doi.org/10.1007/s12544017-0225-0

15. Okunribido OO, Magnusson M, Pope M (2006) Delivery drivers and low-back pain: a study of the exposures to posture demands, manual materials handling and whole-body vibration. Int J Ind Ergonom 36(3):265-273

16. Keyserling WM, Monroe KA, Woolley CB, Ulin SS (1999) Ergonomic considerations in trucking operations: an evaluation of hand truck and ramps. Am Ind Hyg Assoc J 60(1):22-31

17. Blanquart C, Burmeister A (2009) Evaluating the performance of freight transport: a service approach. Eur Transp Res Rev 1(3):135-145

18. EU OSHA (2011) OSH in figures: Occupational safety and health in the Transport sector - an overview. European Agency for Safety and Health at work, European Community Publishing Offices, Luxemburg

19. Croon EM, Blonk RWB, Zwart BCH, Frings-Dresen MHW, Broersen JPJ (2002) Job stress, fatigue, and job dissatisfaction in Dutch lorry drivers: towards an occupation specific model of job demands and control. Occup Environ Med 59(6):356-361
20. Douglas M, Swartz S (2016) Truck driver safety: an evolutionary research approach. Transp J 55(3):258-281

21. Anderson NJ, Smith CK, Byrd JL (2017) Work-related injury factors and safety climate perception in truck drivers. Am J Ind Med 60:711-723

22. Karasek RA, Theorell T (1990) Healthy work: stress, productivity and the reconstruction of working life. Basic Books, New York

23. Brookhuis KA, de Waard D (2010) Monitoring drivers' mental workload in driving simulators using physiological measures. Accid Anal Prev 42:898-903

24. Kadefors R, Forsman M (2000) Ergonomics evaluation of complex work: a participative approach employing video-computer interaction, exemplified in a study of order picking. Int j Ind Ergonom 25(4):435-445

25. Takala EP, Pehkonen I, Forsman M, Hansson GA, Mathiassen SE, Neumann WP, Sjøgaard G, Veiersted KB, Westgaard R, Winkel J (2010) Systematic evaluation of observational methods assessing biomechanical exposures at work- a review. Scand J Work Env Hea 36(1):3-24

26. Larsson G, Johansson A, Jansson T, Grönlund G (2001) Leadership under Severe Stress: A Grounded Theory Study. In: Lester RI, Morton AG (eds) AU-24 Concepts for Air Force Leadership. Air University Press, Alabama, pp 441-447

27. Sbaraini A, Carter SM, Evans RW, Blinkhorn A (2011) How to do a grounded theory study: a worked example of a study of dental practices. BMC Med Res Methodol 11:128

28. Creswell JW (2007) Qualitative inquiry and research design: choosing among five approaches. SAGE, London

29. Williams DF Jr, Thomas SP, Liao-Troth S (2017) The truck driver experience: identifying psychological stressors from the voice of the driver. Transp J 56(1):54-76

30. Van den Heuve SG, Geuskens GA, Hooftman WE, Koppes LL, Van den Bossche VD (2010) Productivity loss at work; health-related and work-related factors. J Occup Rehabil 20(3):331-339

31. Porter ME (1985) Competitive advantage: creating and sustaining superior performance. The Free Press, New York

32. Goffin K, Mitchell R (2010) Innovation Management. Palgrave Macmillan, Hampshire

33. Rajala HK, Väyrynen S (2011) Participative design science approach on the optimum work system: an argumentative review-based model with a case. Theoretical Issues in Ergonomics Science 12(6):533-543

34. Russo F, Comi A (2017) From the analysis of European accident data to safety assessment for planning: the role of good vehicles in urban area. Eur Transp Res Rev 9(9). https://doi.org/10.1007/s12544-017-0225-0

35. Patton MQ (1987) Qualitative research methods. SAGE publications, Beverly Hills

\section{Submit your manuscript to a SpringerOpen ${ }^{\circ}$ journal and benefit from:}

- Convenient online submission

- Rigorous peer review

- Open access: articles freely available online

- High visibility within the field

- Retaining the copyright to your article

Submit your next manuscript at $>$ springeropen.com 